\title{
Melhoria da qualidade do serviço logístico: aplicação de um metódo voltado à redução de devoluções em uma distribuidora de derivados de petróleo
}

\author{
RESUMO
}

Aline Maria Beltrão

Universidade Estadual do Pará (UEPA) Belém, Pará, Brasil

\section{Vitor William Batista Martins}

vitor.martins@uepa.br
Universidade Estadual do Pará (UEPA), Bniversidade Estad Pará, Brasil
O mercado está se tornando cada vez mais competitivo, fazendo com que as empresas busquem vantagens que as auxiliem a alcançar satisfação e fidelização de seus clientes. Em empresas que atuam com distribuição, um dos problemas que influenciam tais objetivos é a devolução de mercadorias que, muitas vezes, acontece por causas relacionadas ao desempenho dos processos logísticos. Portanto, verifica-se a necessidade de melhorar a qualidade destes serviços, de forma a reduzir não-conformidades e aumentar a confiabilidade. Neste sentido, este trabalho objetivou a aplicação de um método voltado à melhoria na qualidade dos serviços logísticos e redução de desperdícios em uma distribuidora de derivados de petróleo, localizada no município de Belém-PA. A aplicação do método gerou o diagnóstico do processo obtendo o componente informação com principal índice de devolução, porém a causa raiz emergencial de o " não possui um sistema de qualidade rígido para inspeção de vasilhames não conformes" surgiu do componente logístico instalação, assim foram criado metas a serem alcançadas como: criação de indicadores de desempenho e treinamentos dos revendedores para buscar a solução/mitigação do problema principal.

PALAVRAS-CHAVE: Componentes Logísticos. Qualidade em Serviços. Devoluções. 


\section{INTRODUÇÃO}

Logística é um termo normalmente associado a atividades como distribuição física, suprimento ou administração de materiais e transporte. Pode-se definir logística como sendo a junção de quatro atividades básicas: aquisição, movimentação, armazenagem e entrega de produtos. Para que estas atividades funcionem é necessário um planejamento logístico, bem como a interação de processos (BALLOU, 2009).

Em decorrência da relevância crescente da logística, uma das exigências é a satisfação do cliente que compreende aspectos relacionados à qualidade em geral, englobando o estado físico do produto, disponibilidade do produto, rapidez e eficiência na entrega, atendimento pelos funcionários que prestam o serviço, entre outros quesitos, fazendo com que as empresas busquem meios de melhorar para obter a qualidade nos processos logísticos, a fim de conquistar a satisfação dos clientes e tornarem-se referência no ramo. Seguindo esta linha de raciocínio, para Oliveira (2010), a exigência da qualidade é um dos requisitos principais por parte dos clientes, além de garantir que a empresa se mantenha no mercado. Sendo assim, as empresas têm se preocupado mais com seus processos e a qualidade de seus produtos e/ou serviços e com a forma como estes estão sendo conduzidos.

Neste contexto, este trabalho foi realizado em uma empresa de distribuição de derivados de petróleo localizada na cidade de Belém, no Estado do Pará que possui como principal produto o GLP (Gás Liquefeito de petróleo) que é uma mistura de gases de hidrocarbonetos utilizado como combustível em aplicações de aquecimento, como fogões por exemplo, onde o gás é armazenado em vasilhames específicos para o consumidor final.

Assim, objetivou-se realizar a aplicação do método criado por Beltrão e Galiza (2015) a identificar motivos para redução de devolução neste processo logístico, mediante a utilização das ferramentas da qualidade, relacionadas aos componentes de desempenho logísticos, dimensionar a qualidade do serviço, direcionar e definir melhorias aos processos logísticos como um todo.

\section{REFERENCIAL TEÓRICO}

\section{COMPONENTES LOGÍSTICOS}

Segundo Alencar e Melo (2012), os componentes logísticos podem ser divididos em duas categorias: Operacionais e Estratégicos. Os componentes operacionais são fortemente ligados ao desenvolvimento das atividades logísticas da organização, devendo ser analisados na proposição de novas estratégias logísticas, bem como na melhoria do desempenho da cadeia de suprimentos em termos de responsividade e eficiência, são eles: Estoques, Transporte, Instalações e Informação (CHOPRA e MEINDL, 2003).

Segundo Ballou (2001), o planejamento logístico tem por objetivo desenvolver estratégias que possam resolver os problemas de quatro áreas de destaque em empresas de transporte que são: o nível de serviços oferecido aos clientes; localização das instalações de centros de distribuição; decisões de níveis de estoque e; decisões de transportes que devem ser utilizados no desenvolvimento 
de todo o processo. Cada uma destas três últimas áreas tem significativo impacto sobre os níveis de serviço ao cliente, existindo uma grande interdependência destes, portanto entende-se que as decisões não podem ser tomadas de forma segmentada. Na Figura 1, são apresentadas as inter-relações das três áreas, formando um triângulo de tomada de decisões logísticas.

Figura 1 - O triângulo de tomada de decisões logísticas

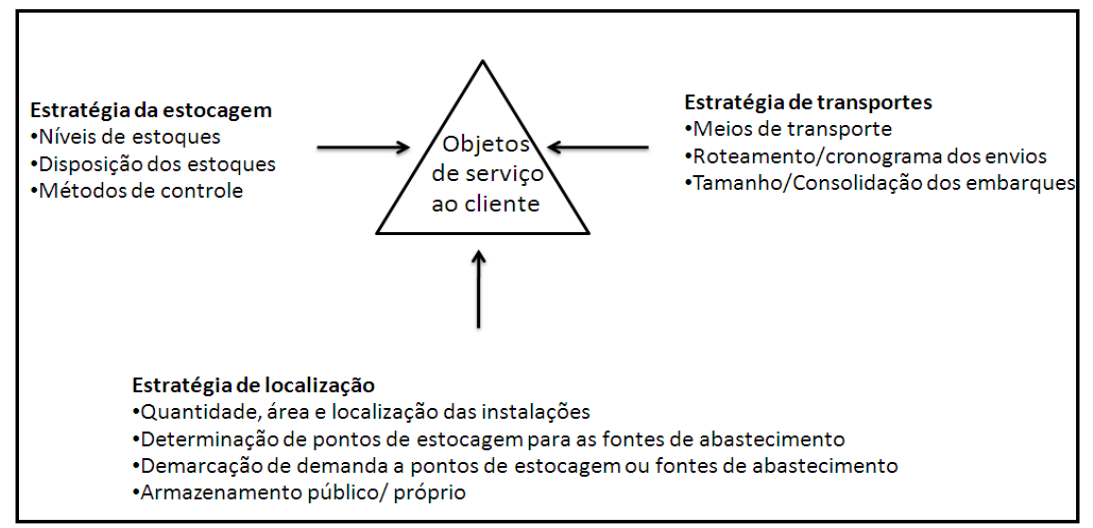

Fonte: Adaptado de Ballou (2006)

\section{Estoque}

Estoques constituem um dos setores que exercem papel de suma importância dentro de uma empresa, por serem eles que mantêm todos os produtos necessários para seu funcionamento, tornando-se essencial em uma gestão eficiente (SILVA E GOMES, 2009).

Para Chopra e Meindl (2003), os estoques têm uma participação crucial na capacidade da cadeia de suprimento em apoiar a estratégia competitiva da empresa. Se a estratégia competitiva exige um alto nível de responsividade, a empresa pode usar os estoques para alcançá-la, disponibilizando grandes quantidades de estoques próximas ao cliente. Contrariamente, a empresa também pode usar os estoques para se tornar mais eficiente, reduzindo-o e, consequentemente, diminuindo seus custos. A escolha implícita sobre os estoques está entre a responsividade, resultante da manutenção de maiores estoques, e a eficiência, resultante de estoques menores.

\section{Instalações}

[...] São os locais físicos reais na rede da cadeia de suprimentos, onde o produto é armazenado, montado ou fabricado. Os dois tipos principais de instalações são locais de produção e locais de armazenamento. Decisões com relação à função, localização, capacidade e flexibilidade das instalações têm um impacto significativo sobre o desempenho da cadeia de suprimentos (CHOPRA e MEINDL, 2011, p. 45).

Incluem-se também nesse componente, as decisões relativas à quais tipos de instalações serão utilizadas na busca da fatia de demanda desejada, isto é, se serão utilizados centros de consolidação ou distribuição, depósitos, lojas, dentre outros. 
O inter-relacionamento dessas decisões se faz por meio de fatores como marketing, custos, disponibilidade de recursos estruturais, de mão de obra e outros.

Para Chopra e Meindl (2003), as instalações e suas respectivas capacidades para desempenhar suas funções são um fator chave de desempenho da cadeia de suprimento em termos de responsividade e eficiência, já que, a partir de decisões sobre instalações, as empresas podem obter economias de escala quando um produto é fabricado e armazenado em apenas um local; essa centralização aumenta a eficiência. Porém, a redução de custos sacrifica a responsividade, pois muitos dos clientes da empresa podem estar distantes da instalação fabril. A decisão sobre o local mais apropriado para as instalações da empresa constitui uma grande parte do projeto da cadeia de suprimentos.

\section{Transporte}

[...] Envolve a movimentação de estoques de um ponto para outro na cadeia de suprimentos. O transporte pode tomar a forma de muitas combinações de modais e de rotas, cada uma com suas próprias características de desempenho. Opções de transporte tem um grande impacto sobre responsividade e eficiência (CHOPRA e MEINDL, 2011, p. 45).

Conforme Ballou (2006), as principais decisões a serem levadas em consideração na estratégia de transportes constituem: seleção de modais de transporte, volume dos embarques e programação de rotas.

É neste componente de desempenho que, geralmente, estão inseridos os maiores custos da cadeia. Portanto, é importante promover seu gerenciamento eficiente, de modo que a melhor decisão seja tomada, visando sempre à máxima agregação de valor de lugar ao cliente (BARBOSA JUNIOR; LEITAO \& MELO, 2009).

Para Chopra e Meindl (2003), o papel do transporte na estratégia competitiva da empresa é representado quando a empresa está avaliando as necessidades de seus clientes. Se o cliente demanda nível alto de responsividade, e está disposta a pagar, a empresa pode então utilizar o transporte como um fator chave para se tornar mais responsiva. Se o cliente tem como critério o preço baixo, a empresa pode utilizar o transporte para baixar os custos e sacrificar a responsividade, com foco na eficiência. Mas as empresas podem utilizar transportes, tentando encontrar um equilíbrio exato entre responsividade e eficiência.

\section{Informação}

[...] Consiste em dados e análise referente a instalações, estoques, transportes, custos, preços e clientes por toda a cadeia de suprimentos. A informação é potencialmente o maior fator-chave de desempenho na cadeia, pois afeta diretamente cada um dos outros fatores. A informação apresenta à gerência a oportunidade de tornar as cadeias de suprimentos mais responsivas e mais eficientes (CHOPRA e MEINDL, 2011, p. 45). 
Ballou (2006) destaca a importância deste componente logístico, quando afirma que a cadeia produtiva inteira é administrada com mais efetividade se todos os membros têm acesso às informações pertinentes à condução de seu negócio. 0 monitoramento das informações não deve se dar somente descendo a cadeia, no sentido do produtor para o cliente (a jusante), mas em ambas as direções (a jusante e a montante).

Segundo Chopra e Meindl (2003), o crescimento vertiginoso da importância da tecnologia da informação é a prova do impacto por ela exercido nas melhorias das empresas. Porém, assim como os outros fatores-chave, a informação exige que as empresas, em um determinado momento, optem entre eficiência e responsividade.

Outra decisão fundamental é escolher qual informação é mais valiosa para a redução de custos e para a melhoria da responsividade dentro da cadeia de suprimento. Essa decisão varia de acordo com a estrutura da cadeia de suprimento e com os segmentos de mercado atendidos.

\section{FERRAMENTA DE QUALIDADE}

A gestão da qualidade é realizada de maneira eficiente quando se aplicam ferramentas que, se utilizadas de forma correta, são capazes de potencializar melhorias no desempenho das empresas que delas fazem uso. Em seguida podemos mencionar algumas delas que foi necessária para aplicação do estudo.

\section{Mapeamento do processo}

Um processo é um grupo de atividades realizadas em uma sequência lógica, com o objetivo de produzir um bem ou um serviço que tem valor para um grupo específico de clientes (HAMMER e CHAMPY, 1994).

Para Harrington (1997), o processo é definido como qualquer atividade que recebe uma entrada (input), agrega-lhe valor (processamento) e gera uma saída (output) para um cliente interno ou externo, fazendo uso dos recursos da organização para gerar resultados concretos. Já para Soliman (1999), um processo integra pessoas, ferramentas e métodos para executar uma sequência de passos, com o objetivo definido de transformar determinadas entradas em saídas.

De maneira geral, um processo é composto de entradas, saídas, tempo, espaço, ordenação, objetivos e valores que resultam em uma estrutura para fornecer serviços e produtos aos clientes. Sua importância nas empresas é confirmada por meio da constatação de que empresas industriais japonesas investem $70 \%$ de seus fundos de pesquisa e desenvolvimento em inovação de processos e têm resultados muito superiores ao de empresas americanas que investem a mesma proporção em desenvolvimento de produtos (GONÇALVES, 2000).

No que se refere ao mapeamento de processos, é possível encontrar na literatura algumas técnicas. Neste artigo, foi utilizada a técnica de fluxograma. Fluxogramas são formas de representar, por meio de símbolos gráficos, a sequência dos passos de um trabalho para facilitar sua análise. Um fluxograma é um recurso visual utilizado pelos gerentes de produção para analisar sistemas 
produtivos, buscando identificar oportunidades de melhorar a eficiência dos processos. (PEINADO; GRAEML, 2007). Para os processos mapeados no presente artigo, utilizou-se, como referência, a simbologia apresentada na Figura 2.

Figura 2 - Legenda do Fluxograma

\begin{tabular}{|c|c|c|c|c|}
\hline Operação & Transporte & Inspeção & Espera & Armazenamento \\
\hline & & & \\
\hline
\end{tabular}

Fonte: Mello (2006)

\section{Diagrama de Pareto}

"O gráfico de Pareto é um gráfico de barras no qual as barras são ordenadas a partir da mais alta até a mais baixa e é traçada uma curva que mostra a porcentagem acumulada de cada barra." (WERKEMA,2006). Como demonstrado na figura 3 .

Figura 3 - Exemplo de Gráfico de Pareto

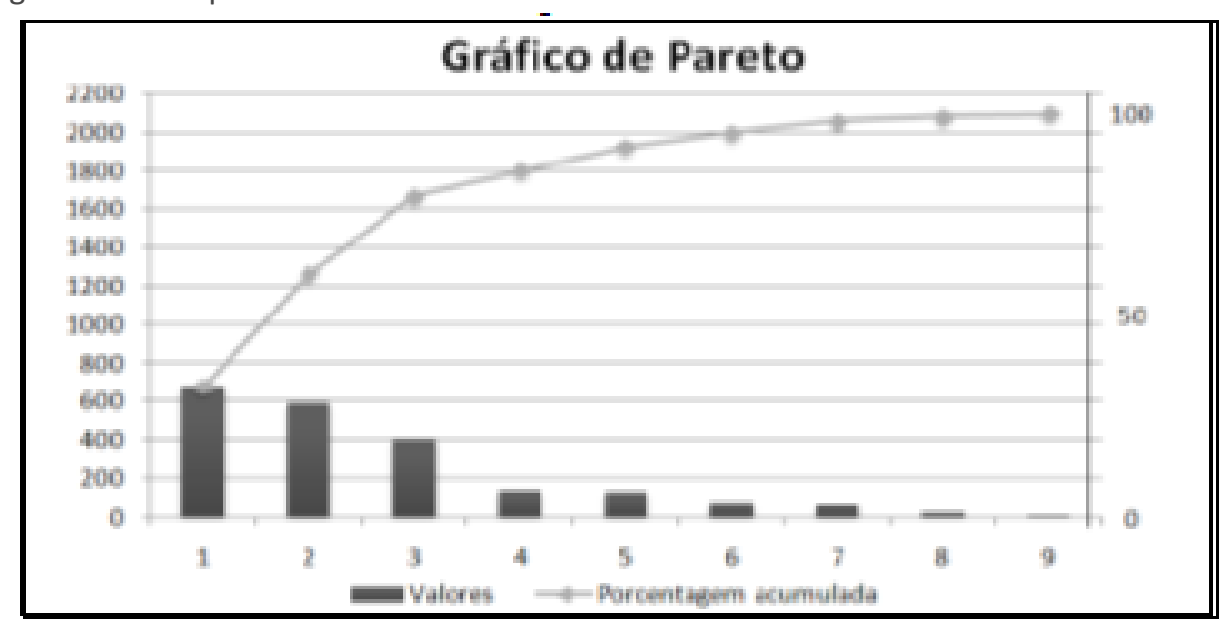

Fonte: Trivellato (2010)

Este gráfico chama a atenção para as categorias mais importantes, ou seja, aquelas que devem ser tratados primeiro no caso das falhas (TRIOLA, 2006).

\section{Diagramas de Causa e Efeito}

O Diagrama de Causa e Efeito, também chamado de Diagrama Espinha de Peixe ou Diagrama de Ishikawa, é um diagrama que visa estabelecer a relação entre o efeito e todas as possíveis causas de um processo. Cada efeito possui várias categorias de causas, que, por sua vez, podem ser compostas por outras causas (RODRIGUES, 2006). Na Figura 4, é mostrado em detalhes o Digrama de Ishikawa.

Basicamente, o resultado do diagrama é fruto de um brainstorming (significa tempestade de ideias), ou seja, pensamentos e ideias que cada membro de um grupo de discussão expõe, sem restrições e democraticamente. $O$ diagrama é um elemento de registro e representação de dados e informação (MIGUEL, 2006). 
Figura 4 - Representação da estrutura do diagrama de causa e efeito (Espinha De Peixe)

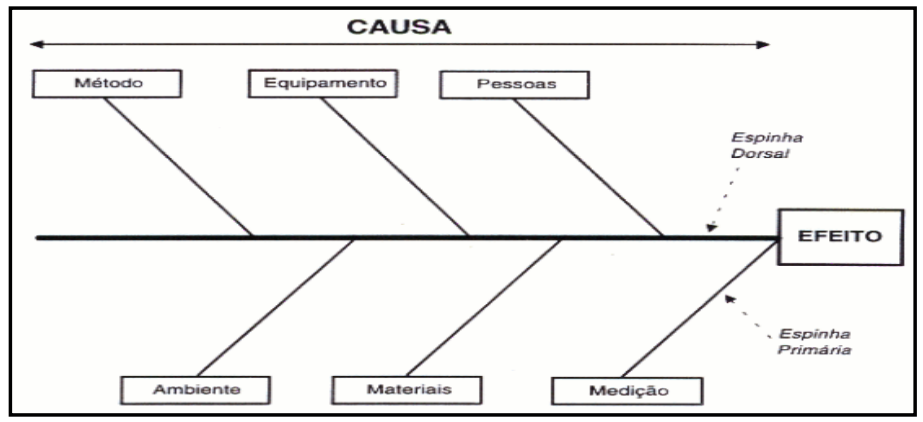

Fonte: Gestão da Qualidade em Saúde (2012)

\section{Método dos cinco porquês}

A técnica dos 5 "porquês" é normalmente utilizada para encontrar a causa raiz de um problema, muito utilizado pelo setor de qualidade das organizações, mais devido à sua versatilidade pode ser utilizada por qualquer setor, conforme afirma Paiva (2007). Belohlavek (2006), explica que os " 5 porquês são" sustentados por diferentes níveis de fundamentação, de acordo com o nível do problema, como mostrado no esquema da Figura 5.

Figura 5 - Pirâmide do Tipo de Abordagem da Realidade

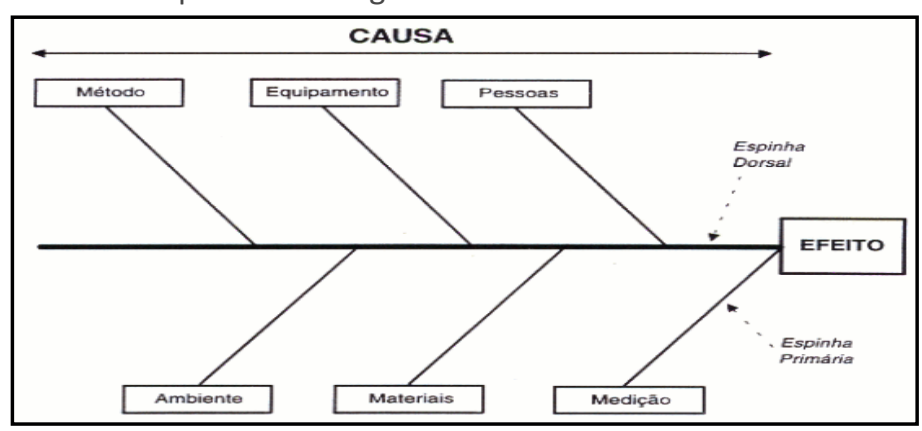

Fonte: Belohlavek (2006)

Ao utilizar-se desta ferramenta, provavelmente serão encontradas várias causas raiz, dependendo de quantas pessoas estejam questionadas, por isso se faz interessante que esta ferramenta seja aplicada a um conjunto de pessoas, para que se gere um debate em torno das causas principais. Somente então é feita a pergunta "Como fazer para resolver este problema?" para que as causas raízes do problema sejam eliminadas ou controladas (Slack et al., 1997; Shingo, 1988).

\section{Matriz GUT}

"Constitui-se de uma ferramenta de grande utilidade para a fixação de prioridades na eliminação de problemas, especialmente se forem vários e relacionados entre si" (BRAGAGNOLO et al.,2004).

Uma análise deve ser feita para cada problema e valores de intensidade serão atribuídos para cada uma das dimensões de GUT, em uma escala de valores de 1 a 5 , onde 1 tem menor intensidade e 5 tem a maior intensidade (TRISTÃO, 2011). 
Após atribuição dos valores de intensidade para cada uma das dimensões de GUT, deve-se multiplicar os valores obtidos para o G, U e T, a fim de se obter um valor para cada problema ou fator de risco estudado (TRISTÃO, 2011). No quadro 1 podemos observa o G.U.T.

Quadro 1 - Exemplo de Matriz GUT

\begin{tabular}{|l|c|c|c|c|}
\hline \multicolumn{1}{|c|}{ Causa logística raiz } & Gravidade & Urgência & $\begin{array}{c}\text { Tendência } \\
\text { Se não for } \\
\text { feita? }\end{array}$ & $\begin{array}{c}\text { Avaliação } \\
\text { da Matriz } \\
\text { (G x U x T ) }\end{array}$ \\
\hline $\begin{array}{l}\text { O revendedor não possui um } \\
\text { mapeamento de seu período } \\
\text { sazonal. }\end{array}$ & 4 & 5 & 4 & 80 \\
\hline $\begin{array}{l}\text { Devido algum erro em seu } \\
\text { sistema/impressão/internet ou } \\
\text { falha no recebimento do XML. }\end{array}$ & 3 & 1 & 1 & 3 \\
\hline $\begin{array}{l}\text { Porque cliente não acompanhou as } \\
\text { pendências fiscais na SEFA. }\end{array}$ & 1 & 3 & 3 & 9 \\
\hline $\begin{array}{l}\text { Devido a falta de comunicação } \\
\text { entre os setores ocorre o desconto } \\
\text { incorreto. }\end{array}$ & 3 & 4 & 4 & 100 \\
\hline $\begin{array}{l}\text { Porque cria pedidos sem o } \\
\text { consentimento do revendedor para } \\
\text { bater a meta. }\end{array}$ & 4 & 5 & 5 & 125 \\
\hline $\begin{array}{l}\text { Pois não possuem um sistema de } \\
\text { qualidade rígido para a verificação } \\
\text { de vasilhames não conformes. }\end{array}$ & 5 & 5 & 5 & 48 \\
\hline
\end{tabular}

Fonte: Adaptado de Grimaldi e Mancuso (1994)

\section{$5 \mathrm{~W} 2 \mathrm{H}$}

O 5W2H é uma técnica utilizada para planejar as ações propostas pelo Diagrama de Causa e Efeito/Diagrama de Ishikawa, como afirma Kume (1993). Segundo Araújo (2006), o plano de ação proposto pelo 5W2H permite especificar, de maneira clara e objetiva, cada ação planejada e é responsável por organizar as tarefas apontadas como relevantes. A ferramenta $5 \mathrm{~W} 2 \mathrm{H}$ auxilia os gestores para as devidas tomadas de ações, em cada tarefa abordada, fazendo as perguntas apresentadas na figura 6 .

Figura 6 - Ferramenta 5W2H

\begin{tabular}{|l|l|l|l|}
\hline Pergunta & Significado & Pergunta Instigadora & Direcionador \\
\hline What? & O quê? & O que deve ser feito? & O objeto \\
\hline Who? & Quem? & Quem é o responsável & O sujeito \\
\hline Where? & Onde? & Onde deve ser feito? & O local \\
\hline When? & Quando? & Quando deve ser feito? & O tempo \\
\hline Why? & Por quê? & Por que é necessário fazer & A razão/motivo \\
\hline How? & Como? & Como será feito? & O método \\
\hline How much? & Quanto custa? & Quanto vai custar? & O valor \\
\hline
\end{tabular}

Fonte: Seleme e Stadler (2008, p. 40) 
Através da utilização desta ferramenta é possível determinar quais serão as ações a serem tomadas e também se pode analisar de que forma os recursos serão alocados.

\section{Meta Smart}

São os resultados a serem obtidos em termos quantitativos e com prazo determinado a partir da execução do plano de ação. É por meio das metas que é possível verificar o quanto os objetivos foram alcançados. Para escrever as metas, recomenda-se adotar a sistemática conhecida como S.M.A.R.T para garantir que sejam específicas, mensuráveis, atingíveis, realistas e temporais. Essas são consideradas as características de boas metas. Vejamos o que significa isso.

Específica : Para ser clara, sua meta precisa ser específica. Metas generalistas não representam fielmente o que se pretende atingir.

Mensurável: Você deve estabelecer critérios para medir o alcance dos resultados, afinal, é como você vai saber o quanto está próximo do que foi planejado.

Atingível: Metas atingíveis precisam apresentar equilíbrio entre o que se pretende alcançar e a capacidade (recursos, estrutura, governabilidade, condições econômicas) de realizar. Não é interessante que sejam exageradamente ousadas - metas quase impossíveis podem desmotivar a equipe -, nem muito fáceis de serem alcançadas, sob o risco de conformismo com a zona de conforto.

Relevante: As metas devem estar articuladas ao seu objetivo maior, ou seja, se não concorrerem de forma importante para o alcance dos objetivos do Plano, não devem ser colocadas como meta.

Temporal: As metas definidas precisam de prazo para serem alcançadas. Do contrário torna-se impossível monitorar se o Plano está no rumo adequado ou se precisa de ajustes.

\section{Método de melhoria da qualidade do serviço logístico}

Neste capitulo, apresenta-se o método criado por Beltrão e Galiza (2015) e aplicado nesta pesquisa. De forma geral, o método é constituído por 6 passos, organizados em uma sequência lógica, sendo cada um destes trabalhado por meio da utilização de uma ou mais ferramentas ou abordagens associadas à Logística ou à Qualidade em Serviços, já apresentadas na literatura. Ressalta-se que o método é estruturado, considerando o emprego de ferramentas ou abordagens em uma sequência de passos, nos quais cada resultado gerado constitue os dados de entrada do passo sequente. Ao final da aplicação do método, gera-se um plano de ações de melhorias logísticas voltadas à resolução dos motivos de um dado problema que se deseja mitigar ou solucionar completamente.

De forma objetiva, conforme Beltrão e Galiza (2015), o método de melhoria da qualidade do serviço logístico pode ser decomposto em 6 etapas ou passos, descritos a seguir, e ilustrados na Figura 7:

a) 10 Passo - Identificação do problema e das causas associadas 
Dentro do processo analisado, um problema principal/norteador deve ser identificado e, a partir desta identificação, realiza-se o levantamento de suas possíveis causas, as quais devm ser coletadas a partir de bancos de dados ou arquivos de documentos, entrevistas ou reuniões com o pessoal diretamente envolvido e observações in loco. Ressalta-se que todos os problemas devem ser definidos conforme o ponto de vista da organização onde o método estiver sendo aplicado. As informações coletadas, referentes às frequências de ocorrências, devem ser de, no mínimo, 12 meses. O conhecimento sobre o processo deve ocorrer de maneira prática, analisando-se documentos internos e acompanhando cada atividade presencialmente, para identificar os recursos envolvidos. Ao final desta etapa, deve-se criar além do desenho do processo considerado, um relatório com uma lista de problemas associados aos seus graus de impactos para o desempenho da organização e um texto descritivo de todos os problemas, conforme a ótica da organização.

b) 2 ㅇ Passo - Associação das causas do problema à logística

As possíveis causas gerais relacionadas ao problema principal, devem ser, então, associadas às operações logísticas envolvidas com o desenvolvimento do processo. Para tal, deve-se identificar e justificar as possíveis relações entre estas causas diretas do problema principal e os componentes logísticos operacionais (Estoque, instalação, transportes e informação) diretamente envolvidos na execução do processo em estudo. Ao final desta etapa, apresenta-se um documento com todas as causas gerais, relacionadas ao problema principal, associadas a, pelo menos, um dos componentes logísticos operacionais e um texto descritivo com a justificativa de cada associação realizada entre as causas do problema e os componentes logísticos.

c) 3o Passo - Identificação das causas logísticas relacionadas ao problema

Nesta etapa, a partir dos resultados da etapa anterior, para cada componente logístico operacional, devem-se identificar as causas logísticas que apresentam a maior frequência de ocorrências e associar essas causas ao problema principal objeto da pesquisa. A identificação das causas logísticas principais deve ser realizada somente se houver a necessidade de se trabalhar de forma gradual para solução de todas as causas do problema principal, tendo em vista que é necessário identificar quais as causas que tem maior ocorrência na organização objeto de aplicação do método. Quando existir um pequeno grupo de causas, onde todas possam ser solucionadas conjuntamente, essa etapa não se faz necessária, passando direto para o próximo passo do método. Ao final, gera-se um documento com um ranking das principais causas logísticas junto com um documento associando essas causas logísticas ao seu problema principal.

d) 4o Passo - Identificação das principais causas logísticas raízes do problema

De acordo com as causas identificadas nos passos anteriores, nesta etapa se realizam as as perguntas sobre os "porquês" das causas acontecerem, repetindose sempre com a resposta da anterior, em busca da causa raiz deste problema. Ao final desta etapa, uma lista com as possíveis causas logísticas raízes, associadas, por componente logístico operacional, ao problema principal deverá ser disponibilizada.

e) 5o Passo - Hierarquização das causas logísticas raízes do problema 
Nesta etapa, será definida a prioridade de atendimento/resolução das causas logísticas raízes associadas ao problema principal. Para tal, deve-se considerar a análise de três requisitos, a saber: Gravidade, Urgência e Tendência associadas às referidas causas logísticas raízes, que deve ocorrer através da realização de um brainstorming, com os principais gestores da empresa envolvidos pela busca da melhoria do processo logístico. Ao final desta etapa, será gerado um quadro com um ranking, destacando a influência de cada causa logística raiz para o surgimento do problema principal.

f) 6o Passo - Proposição de ações de melhorias logísticas para eliminação/mitigação do problema

Para esta etapa, deve-se propor um plano de ações, com vistas a solucionar as principais causas logísticas operacionais raízes geradoras do problema principal/ norteador, trabalhadas nas etapas anteriores do método. 0 plano de ações deve ser organizado por meio do estabelecimento de objetivos e procedimentos necessários para o fornecimento de resultados, onde se deve atender aos requisitos do cliente e às politicas (estratégicas, táticas e operacionais) da organização. Para isso, algumas premissas, convertidas em questões, devem ser consideradas, com base na ferramenta $5 \mathrm{~W} 2 \mathrm{H}$. A vantagem de uso deste plano de ações é que, com ele, a empresa terá em mãos um instrumento simples e eficaz de implantação de melhorias logísticas, caso todos os campos sejam preenchidos corretamente e completamente. No momento de sua execução, todas as premissas descritas devem ser analisadas periodicamente para verificação de suas eficácias. Por fim, todas as ações tomadas que tenham se tornado eficazes para solução das causas logísticas raízes e, consequentemente, do problema principal, deve ser transformadas em procedimentos padrões.

Ao final destas etapas, deve ser gerado um documento com ações criadas para solucionar de forma total ou mitigar as causas do problema principal, todas as etapas devem ser executadas conforme os prazos pré-determinados na criação dessas ações, onde serão verificados seus resultados, após esse prazo, e corrigidas, conforme necessidade encontrada, durante suas fases de execução e verificação. 
Figura 7 - Quadro resumo dos passos do método proposto

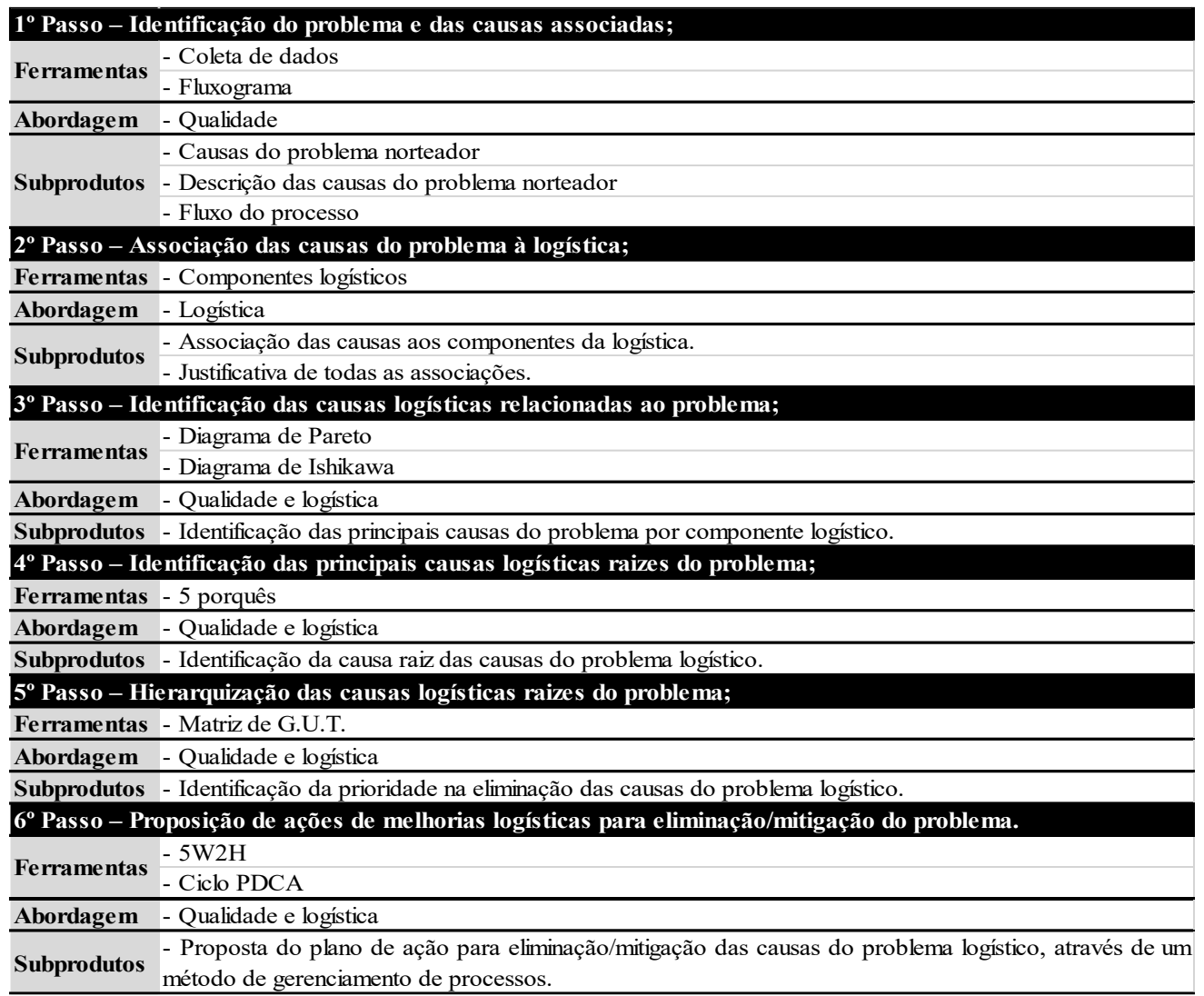

Fonte: Beltrão e Galiza (2015)

\section{ESTUDO DE CASO}

\section{CARACTERIZAÇÃO DA EMPRESA}

Fundada há 60 anos, a distribuidora de gás liquefeito de petróleo (GLP), onde se desenvolveu este trabalho, chega aos dias atuais com o foco na modernidade, com destaque nacional no segmento de gás domiciliar e crescendo cada dia mais, sua base da filial Belém está instalada no Terminal Petroquímico, da Companhia Docas do Pará, na Avenida Salgado Filho, S/N, no bairro de Miramar, apresentando-se como a principal base envasadora de gás LP da cidade.

\section{CARACTERIZAÇÃO DA OPERAÇÃO E DO PROBLEMA EM ANÁLISE}

A partir de uma análise inicial e do processo analisado mediante ao mapeamento das atividades, foi diagnosticado um problema principal, que constituiu a Devolução de vasilhames, os produtos são retornados, havendo assim um gargalo no processo de carregamento pois quando os caminhões chegam com estes produtos no cliente ou base deverá realizar a separação desses vasilhames para colocar em locais adequados, seja dentro do caminhão para não atrapalhar o processo de descarregamento ou na base, causando assim insatisfação de clientes, gerando um aumento significativo nos custos logísticos da empresa, já que gera 
perdas de tempo, de produtividade, movimentação, e até mesmo, de clientes. Além disso, a empresa ainda tem que assumir todas as despesas referentes à viagem desnecessária dos produtos devolvidos, gerando grande prejuízo.

\section{ANÁLISE E DISCURSÕES DOS RESULTADOS}

\section{1ํ passo - identificação do problema e das causas associadas}

\section{Causas do problema norteador}

Durante a coleta de dados foi concebida uma planilha (ver Tabela 1) com os dados correspondentes a um período de 12 meses.

Tabela 1 - Dados coletados referente a devolução de produtos

\begin{tabular}{|c|c|c|c|c|}
\hline & MOTIVO & NF'S & $\%$ & VL TOTAL \\
\hline 1 & NÃO DISPOR DOS VASILHAMES VAZIOS & 297 & $36,99 \%$ & $\mathrm{R} \$ 1.522 .691,32$ \\
\hline 2 & VASILHAMES COM NÃO CONFORMIDADE & 139 & $17,31 \%$ & $\mathrm{R} \$ 353.693,11$ \\
\hline 3 & $\begin{array}{l}\text { CLIENTE NÃO EMITIU NOTA FISCAL DE } \\
\text { RETORNO DOS VASILHAMES }\end{array}$ & 75 & $9,34 \%$ & $\mathrm{R} \$ 198.618,79$ \\
\hline 4 & CLIENTE NÃO HABILITADO NO SINTEGRA & 50 & $6,23 \%$ & $\mathrm{R} \$ 231.989,82$ \\
\hline 5 & DESCONTO INCORRETO & 50 & $6,23 \%$ & $\mathrm{R} \$ 468.718,51$ \\
\hline 6 & CLIENTE NÃO SOLICITOU O PEDIDO & 50 & $6,23 \%$ & $\mathrm{R} \$ 281.007,76$ \\
\hline 7 & ESTABELECIMENTO ENCONTRA-SE FECHADO & 44 & $5,48 \%$ & $\mathrm{R} \$ 143.278,78$ \\
\hline 8 & QUANTIDADE INCORRETA & 33 & $4,11 \%$ & $\mathrm{R} \$ 269.638,70$ \\
\hline 9 & EMISSÃO INDEVIDA & 29 & $3,61 \%$ & $\mathrm{R} \$ 343.386,17$ \\
\hline 10 & PROBLEMAS NO SISTEMA & 18 & $2,24 \%$ & $\mathrm{R} \$ 100.795,31$ \\
\hline 11 & CLIENTE BLOQUEADO PELA COBRANÇA & 13 & $1,62 \%$ & $\mathrm{R} \$ 195.517,40$ \\
\hline 12 & $\begin{array}{l}\text { CLIENTE SÓ ACEITA NOTA FISCAL } \\
\text { ELETRÔNICA }\end{array}$ & 5 & $0,62 \%$ & $R \$ 5.474,05$ \\
\hline & Total & 803 & $100,00 \%$ & $\mathrm{R} \$ 4.114 .809,72$ \\
\hline
\end{tabular}

Fonte: Autoria própria (2017)

A empresa deixou de faturar um valor bruto de $\mathrm{R} \$ 4.114 .809,72$ levando em consideração o quantitativo de produtos devolvidos conforme tabela 1, somando os custos diretos referentes aos gastos intrínsecos ao processo logístico ocorrido durante as devoluções, considerando também os custos indiretos como insatisfação dos clientes e os efeitos negativos gerados a imagem da empresa.

\section{Fluxo do processo}

O fluxo do processo da empresa estudada foi descrito conforme as necessidades de levantamento de fluxos para esse trabalho, onde as etapas foram subdivididas em três áreas, a saber: venda, logística e faturamento.

Assim, o processo de vendas funciona da seguinte forma: o setor de célula de atendimento realiza a programação de acordo com a solicitação do 
revendedor, ao término, envia a programação para a análise de crédito, que irá realizar a verificação de créditos dos revendedores e seus pagamentos, e também é destinada para o setor de logística.

No Setor de Logística, ao receber a programação da célula de atendimento monta-se a roteirização dos revendedores programados. No dia seguinte será feito o filtro dos clientes liberados pela cobrança e assim é passado a autorização de carregamento para o setor de faturamento. Enquanto isso o motorista posicionase o caminhão para realizar o carregamento, após o término o motorista pega a nota fiscal e segue para realizar entregas nas revendas.

No setor de faturamento, realiza-se a emissão de notas ficais e análise dos clientes que se encontra não habilitados no sintegra. Em seguida pode-se verificar o fluxograma mediante a figura 8.

2o Passo - Associação das causas do problema à logística

\section{Justificativa de todas as associações}

Após o levantamento dos dados descritos na Tabela 1, foram levantadas com auxílio da empresa, 12 causas que geram a devolução de mercadorias (problema principal) na empresa objeto de aplicação do método proposto. Estas causas foram caracterizadas conforme o ponto de vista da empresa, como demonstrado no Quadro 2. 
Figura 8 - Fluxograma do processo da empresa

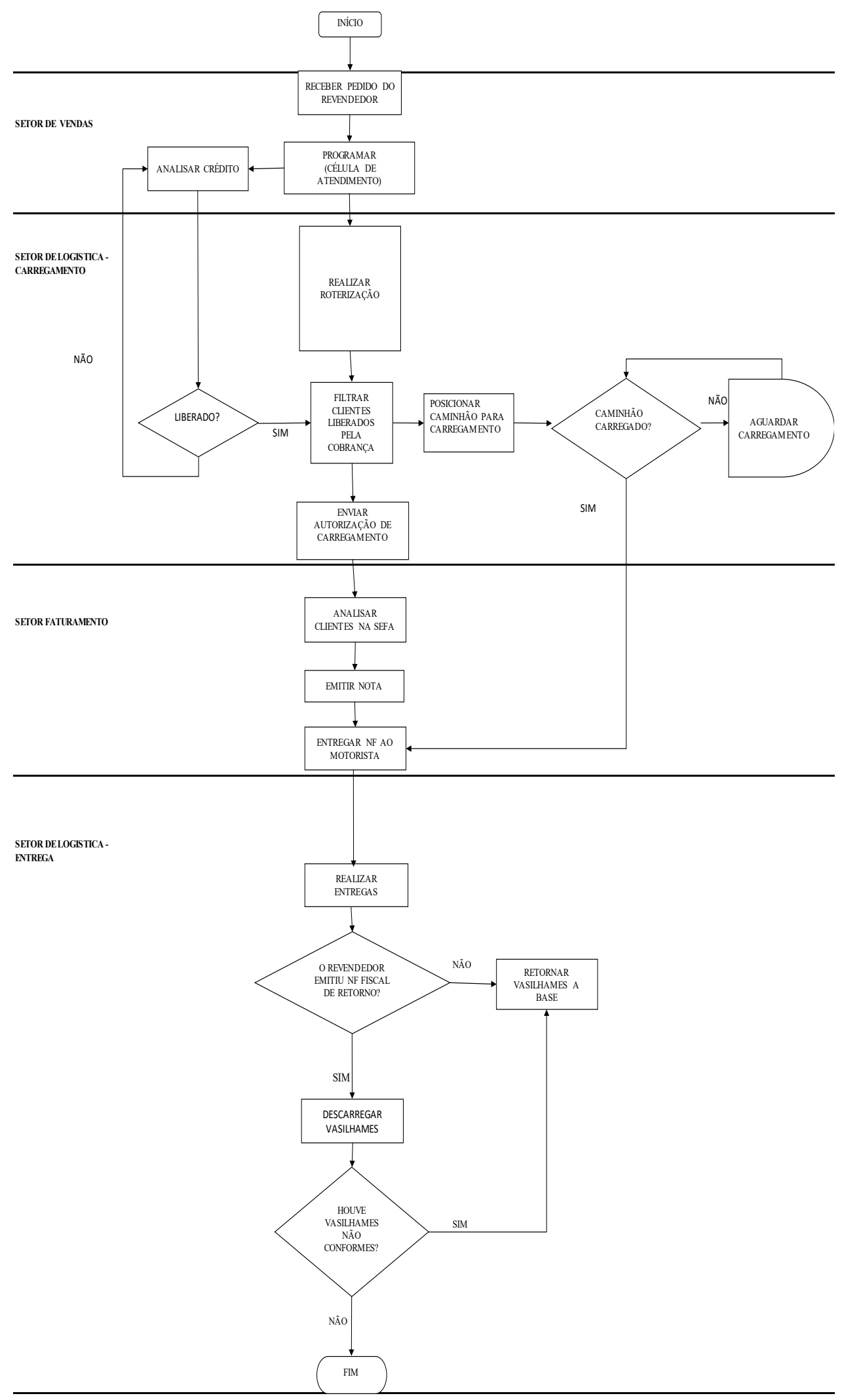


Fonte: Autoria própria (2017)

Quadro 2 - Descrição dos motivos

\begin{tabular}{|c|c|}
\hline MOTIVO & DESCRIÇÃO \\
\hline $\begin{array}{l}\text { Cliente bloqueado pela } \\
\text { cobrança: }\end{array}$ & $\begin{array}{l}\text { Ocorre quando o cliente atinge um limite de pedido e } \\
\text { seu saldo ainda não baixou devido ao pagamento não } \\
\text { efetuado; }\end{array}$ \\
\hline $\begin{array}{l}\text { Cliente não emitiu nota } \\
\text { fiscal de retorno dos } \\
\text { vasilhames: }\end{array}$ & $\begin{array}{l}\text { Ocorrer quando o cliente não recebe o XML da nota para } \\
\text { emissão ou problema no computador do cliente; }\end{array}$ \\
\hline $\begin{array}{l}\text { Cliente só aceita nota } \\
\text { fiscal eletrônica: }\end{array}$ & $\begin{array}{l}\text { Ocorre quando a célula de atendimento programa seu } \\
\text { pedido para emissão de nota fiscal manual sendo que o } \\
\text { cliente só aceita nota fiscal eletrônica; }\end{array}$ \\
\hline $\begin{array}{l}\text { Não dispor dos vasilhames } \\
\text { vazios: }\end{array}$ & $\begin{array}{l}\text { Ocorre quando o cliente não possui vasilhames vazios } \\
\text { para efetuar a troca para vasilhames cheios, caso falte } \\
\text { um vasilhame o mesmo deverá retornar com toda } \\
\text { mercadoria, exceto os clientes que aceitaram nota } \\
\text { manual que poderá ser feito ajuste na hora; }\end{array}$ \\
\hline Problemas no sistema: & $\begin{array}{l}\text { Ocorre quando o sistema de administração de gás (SAG) } \\
\text { encontra-se fora do ar em manutenção inconsistência, } \\
\text { com isso o sistema fica inoperante; }\end{array}$ \\
\hline Quantidade incorreta: & $\begin{array}{c}\text { Ocorre quando existe divergência no que o cliente pediu } \\
\text { e no que foi programado para atender o cliente; }\end{array}$ \\
\hline $\begin{array}{l}\text { Cliente não habilitado no } \\
\text { Sintegra: }\end{array}$ & $\begin{array}{l}\text { Ocorre quando o cliente possui alguma irregularidade no } \\
\text { CNPJ, não permitindo o faturamento da nota fiscal para o } \\
\text { cliente. Como os pedidos são faturados após o } \\
\text { carregamento da carga, mesmo que não seja possível } \\
\text { faturar pedidos para alguns clientes, as mercadorias } \\
\text { acabam não sendo retiradas dos veículos, para não } \\
\text { atrapalhar a logística; }\end{array}$ \\
\hline $\begin{array}{l}\text { Cliente Não Solicitou o } \\
\text { Pedido: }\end{array}$ & $\begin{array}{l}\text { Ocorre quando os pedidos que não foram aceitos pelos } \\
\text { clientes, pois os mesmos alegam que não fizeram a } \\
\text { solicitação; }\end{array}$ \\
\hline $\begin{array}{l}\text { Vasilhames não } \\
\text { conformes: }\end{array}$ & $\begin{array}{c}\text { Ocorre quando os pedidos que não foram aceitos pelos } \\
\text { clientes, pois a mercadoria chegou com avarias este erro } \\
\text { acontece ou no momento do transporte, quando a carga } \\
\text { sofre avarias, por não estar totalmente presa, ou no } \\
\text { momento da descarga no cliente, por descuido no } \\
\text { carregamento; }\end{array}$ \\
\hline Emissão indevida: & $\begin{array}{l}\text { Ocorre quando o faturista emite uma nota fiscal que não } \\
\text { foi programada para a data atual. }\end{array}$ \\
\hline $\begin{array}{l}\text { Cliente encontra-se } \\
\text { fechado: }\end{array}$ & $\begin{array}{l}\text { Ocorre quando os pedidos que não foram aceitos pelos } \\
\text { clientes, pois, no momento da entrega da mercadoria, o } \\
\text { cliente se encontrava fechado este motivo acontece, } \\
\text { pois, o cliente não atualizou seu horário de entregas na } \\
\text { distribuidora e, assim, a distribuidora foi entregar fora do } \\
\text { horário comercial. }\end{array}$ \\
\hline Desconto incorreto: & $\begin{array}{c}\text { Ocorre quando não está programado o desconto no } \\
\text { produto do cliente. }\end{array}$ \\
\hline
\end{tabular}

Fonte: Autoria própria (2017) 
Quadro 3 - Associação dos motivos de devoluções aos componentes logísticos

\begin{tabular}{|c|c|c|c|c|c|c|c|}
\hline & 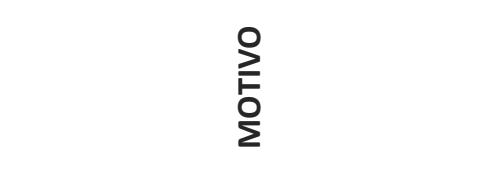 & $\frac{n}{z}$ & 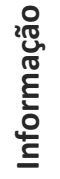 & $\begin{array}{l}\frac{0}{\partial} \\
\frac{5}{\circ} \\
\stackrel{4}{4}\end{array}$ & 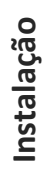 & $\begin{array}{l}\stackrel{0}{t} \\
\frac{1}{0} \\
\frac{0}{n} \\
\frac{c}{0} \\
=\end{array}$ & do \\
\hline 1 & Não dispor dos vasilhames vazios & 297 & $\mathrm{X}$ & & & & $36,99 \%$ \\
\hline 2 & $\begin{array}{l}\text { Vasilhames com não } \\
\text { conformidade }\end{array}$ & 139 & & & $\mathrm{x}$ & & $17,31 \%$ \\
\hline 3 & $\begin{array}{l}\text { Cliente não emitiu NF de retorno } \\
\text { dos vasilhames }\end{array}$ & 75 & $\mathrm{X}$ & & & & $9,34 \%$ \\
\hline 4 & Cliente não habilitado no sintegra & 50 & $\mathrm{X}$ & & & & $6,23 \%$ \\
\hline 5 & Desconto incorreto & 50 & $\mathrm{X}$ & & & & $6,23 \%$ \\
\hline 6 & Cliente não solicitou o pedido & 50 & $\mathrm{X}$ & & & & $6,23 \%$ \\
\hline 7 & $\begin{array}{l}\text { Estabelecimento encontra-se } \\
\text { fechado }\end{array}$ & 44 & $\mathrm{x}$ & & & & $5,48 \%$ \\
\hline 8 & Quantidade incorreta & 33 & $x$ & & & & $4,11 \%$ \\
\hline 9 & Emissão indevida & 29 & $\mathrm{X}$ & & & & $3,61 \%$ \\
\hline 10 & Problemas no sistema & 18 & $\mathrm{x}$ & & & & $2,24 \%$ \\
\hline 11 & Cliente bloqueado pela cobrança & 13 & $\mathrm{X}$ & & & & $1,62 \%$ \\
\hline 12 & $\begin{array}{l}\text { Cliente só aceita nota fiscal } \\
\text { eletrônica }\end{array}$ & 5 & $x$ & & & & $0,62 \%$ \\
\hline & Total & 803 & & & & & $100,00 \%$ \\
\hline
\end{tabular}

Fonte: Autoria própria (2017)

Foi possível verificar, após análise do Quadro 3, que das 12 causas associadas, 1 foi associada ao componente Instalação e 11 foram associadas ao componente informação. No tabela 2, apresenta-se a distribuição de causas de devoluções associados por componente logístico.

Tabela 2 - Percentual de devoluções por componente logístico associado

\begin{tabular}{cc} 
COMPONENTE LOGÍSTICO & $\%$ \\
INFORMAÇÃO & $98,04 \%$ \\
TRANSPORTES & $0,00 \%$ \\
ESTOQUE & $0,00 \%$ \\
INSTALAÇÃO & $1,96 \%$ \\
\hline
\end{tabular}

Fonte: Autoria própria (2017)

Após a finalização da etapa 2, foi possível observar, no tabela 2, que o componente logístico informação foi o que produzia maior influência dentro do processo logístico da empresa, totalizando 98,04\% de ocorrência dentro das causas levantadas. Foi possível, também, observar que nenhuma das causas levantadas na Etapa 1 têm associação com o componente transporte e estoque. Dessa forma, para as próximas etapas de desenvolvimento do método, este componente logístico não será abordado. 


\section{3o Passo - identificação das causas logísticas relacionadas ao problema}

\section{Identificação das principais causas do problema por componente logístico}

Foi aplicado, para cada componente logístico, o Diagrama de Pareto. Os resultados desta aplicação do componente logístico informação encontra-se ilustrado na figura 9 e tabela 3 presentes a seguir:

Figura 9 - Gráfico de Pareto dos motivos de devolução do componente logístico transportes

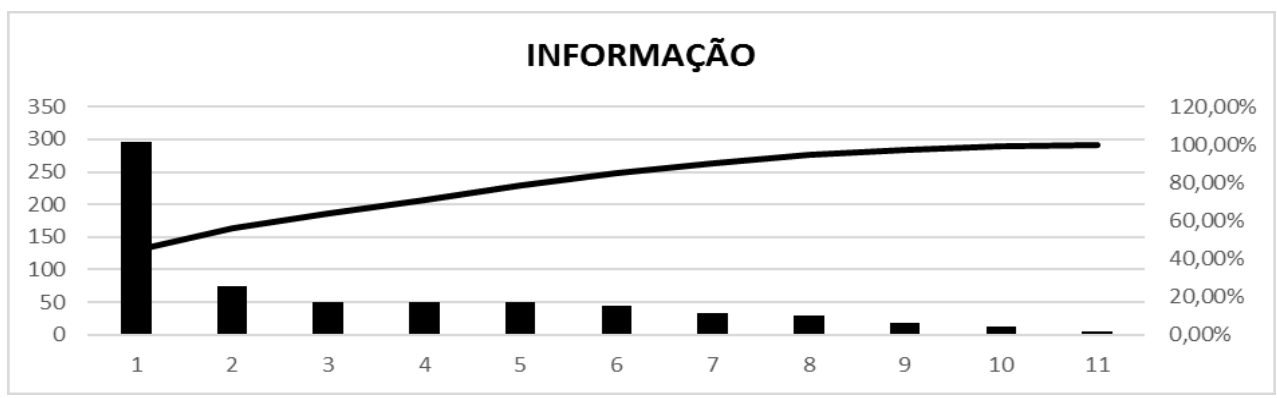

Fonte: Autoria própria (2017)

Tabela 3 - Base de dados gráfico 3

\begin{tabular}{|c|c|c|c|c|}
\hline & Motivo & NF'S & $\%$ & $\%$ Acumulada \\
\hline 1 & Não dispor dos vasilhames vazios. & 297 & $44,73 \%$ & $44,73 \%$ \\
\hline 2 & $\begin{array}{l}\text { Cliente não emitiu nota fiscal de retorno dos } \\
\text { vasilhames. }\end{array}$ & 75 & $11,30 \%$ & $56,02 \%$ \\
\hline 3 & Cliente não habilitado no sintegra & 50 & $7,53 \%$ & $63,55 \%$ \\
\hline 4 & Desconto incorreto & 50 & $7,53 \%$ & $71,08 \%$ \\
\hline 5 & Cliente não solicitou o pedido & 50 & $7,53 \%$ & $78,61 \%$ \\
\hline 6 & Estabelecimento encontra-se fechado & 44 & $6,63 \%$ & $85,24 \%$ \\
\hline 7 & Quantidade incorreta. & 33 & $4,97 \%$ & $90,21 \%$ \\
\hline 8 & Emissão indevida. & 29 & $4,37 \%$ & $94,58 \%$ \\
\hline 9 & Problemas no sistema & 18 & $2,71 \%$ & $97,29 \%$ \\
\hline 10 & Cliente bloqueado pela cobrança & 13 & $1,96 \%$ & $99,25 \%$ \\
\hline 11 & Cliente só aceita nota fiscal eletrônica & 5 & $0,75 \%$ & $100,00 \%$ \\
\hline & TOTA & 664 & $100 \%$ & \\
\hline
\end{tabular}

Fonte: Autoria própria (2017)

Após análise do Gráfico 3, com informações referentes ao componente logístico informação, foi possível observar que o motivo que maior influenciou esse componente foi NÃO DISPOR DE VASILHAMES VAZIOS, com 44,73\% de ocorrências.

O componente logístico instalação não houve necessidade de realizar aplicação devido obter única relação a causa deste foi VASILHAMES COM NÃO CONFORMIDADE. 
A aplicação do Diagrama de Pareto permitiu construir um quadro resumo (Quadro 4), contendo as principais causas associadas a cada componente logístico. Esta tabela foi criada utilizando como base $80 \%$ dos motivos de cada componente logístico, porcentagem essa considerada como critério do aplicador do método, como ponto de corte e classi ficação dos motivos considerados emergenciais, assim dando continuidade a aplicação do método.

Quadro 4 - Resumo dos principais motivos dos componentes logísticos

\begin{tabular}{|c|c|l|c|r|}
\hline $\begin{array}{c}\text { Componente } \\
\text { Logístico }\end{array}$ & Qnt & \multicolumn{1}{|c|}{ Motivo } & NF'S & $\%$ \\
\hline \multirow{4}{*}{ Informação } & 1 & Não dispor dos vasilhames vazios. & 297 & $44,73 \%$ \\
\cline { 2 - 5 } & 2 & $\begin{array}{l}\text { Cliente não emitiu nota fiscal de retorno } \\
\text { dos vasilhames }\end{array}$ & 75 & $56,02 \%$ \\
\cline { 2 - 5 } & 3 & Cliente não habilitado no sintegra & 50 & $63,55 \%$ \\
\cline { 2 - 5 } & 4 & Desconto incorreto & 50 & $71,08 \%$ \\
\cline { 2 - 5 } & 5 & Cliente não solicitou o pedido & 50 & $78,61 \%$ \\
\hline Instalação & 1 & Vasilhames com não conformidade & 139 & $100,00 \%$ \\
\hline
\end{tabular}

Fonte: Autoria própria (2017)

A partir da análise da Quadro 4, é possível observar que há 6 principais causas de devoluções, três das quais somam, no componente logístico informação, mais de $60 \%$ das ocorrências que geram o problema de devoluções na empresa. Essas principais causas selecionadas foram consideradas as causas principais do efeito devolução e serão ilustrados com base na aplicação do Diagrama de Causa e Efeito (Ishikawa).

Figura 10 - Diagrama de Ishikawa das causas do problema da empresa

\section{Diagrama de Causa e Efeito}

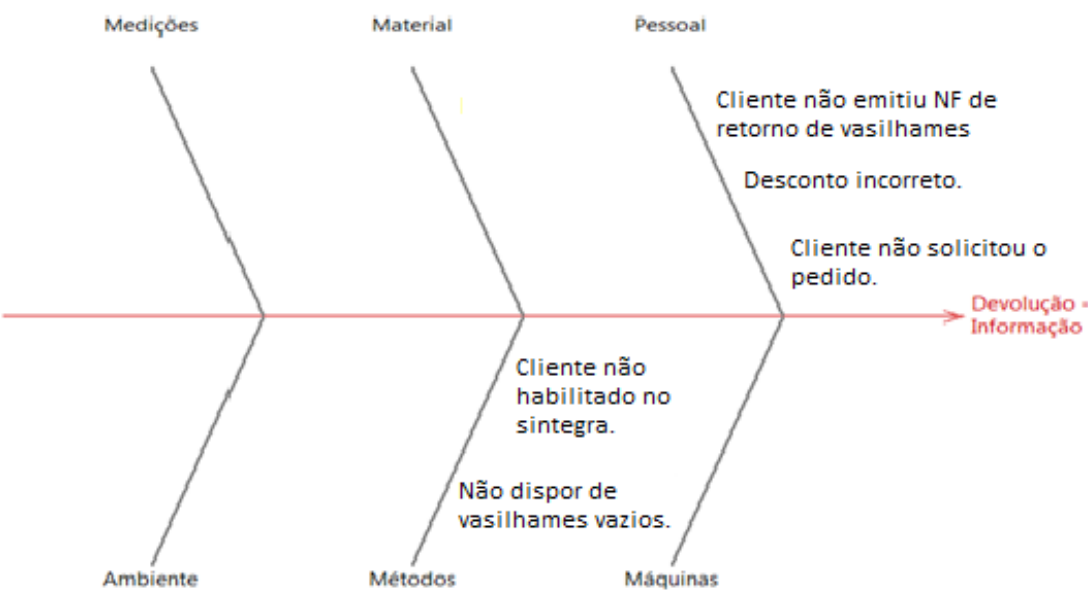

Fonte: Autoria própria (2017)

Após ilustração na Figura 10, pode-se observar que a causa que fez referência ao efeito DEVOLUÇÃO-INFORMAÇÃO, a causa CLIENTE NÃO HABILITADO NO SINTEGRA e NÃO DISPOR DE VASILHAMES VAZIOS fez referência ao método do efeito norteador, CLIENTE NÃO EMITIU NF DE RETORNO DE VASILHAMES, DESCONTO INCORRETO e CLIENTE NÃO SOLICITOU O PEDIDO fez referência ao pessoal do efeito norteador. 
Figura 11 - Diagrama de Ishikawa das causas do problema da empresa

\section{Diagrama de Causa e Efeito}

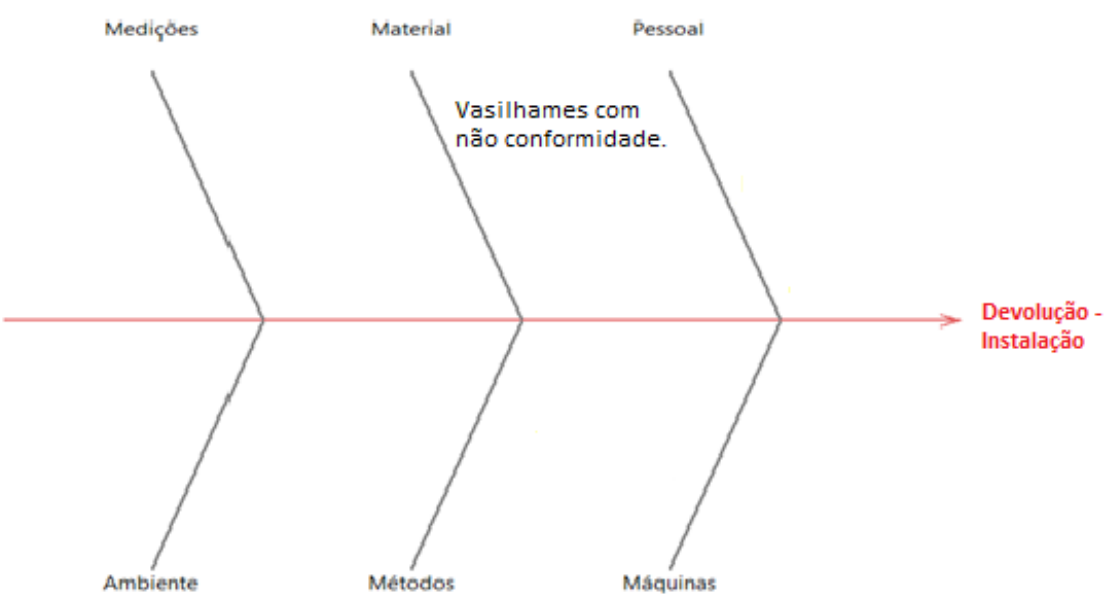

Fonte: Autoria própria (2017)

Após ilustração na Figura 11, a causa referente ao efeito DEVOLUÇÃOINSTALAÇÃO, foi possível observar que a causa VASILHAMES COM NÃO CONFORMIDADE fez referência ao material do efeito norteador.

\section{4ㅇ Passo - identificação das causas logísticas raízes do problema}

Em seguida, as causas identificadas como emergenciais na etapa anterior, foram analisadas junto à ferramenta da qualidade " 5 porquês", com vistas á identificação das causas raízes logísticas associadas ao problema de cada, ao realizar os questionamentos foi possível verificar que identificou-se sua causa-raiz antes dos " 5 porquês" conforme apresentado no apêndice A.

\section{5o Passo - Hierarquização das causas logísticas raízes do problema}

\section{Identificação da prioridade na eliminação das causas do problema logístico}

Nesta etapa, os itens considerados, no Quadro 5, causas logísticas raízes, foram validados sob o ponto de vista de gravidade, urgência e tendência, de modo a identificar qual a causa logística raiz mais impactante para geração do problema principal. Essa avaliação foi feita com a ferramenta MATRIZ DE G.U.T.

Após análise realizada pela matriz de GUT, presente no Quadro 6, a causa apontada com maior urgência para sua mitigação/solução foi " Pois não possuem um sistemade qualidade rígido para a verificação de vasilahmes não conformes.", com uma avaliação de 125 pontos devido a ocorrencia de perda de clientes mensionadas devido a este motivo. 
Quadro 5 - Resumo das causa raiz por componentes logísticos

\begin{tabular}{|r|r|}
\hline \multicolumn{2}{|c|}{ INFORMAÇÃO - Motivo - NÃO DISPOR DOS VASILHAMES VAZIOS. } \\
\hline 4 Porquê? & Por que o revendedor não possui uma demanda prevista? \\
\hline Causa Raiz & O revendedor não possui um mapeamento de seu período sazonal. \\
\hline INFORMAÇÃO - Motivo - CLIENTE NÃO EMITIU NOTA FISCAL DE RETORNO DOS \\
VASILHAMES.
\end{tabular}

Fonte: Autoria própria (2017)

Quadro 6 - Matriz de GUT para as principais causas logísticas raízes de devolução

\begin{tabular}{|c|c|c|c|c|}
\hline 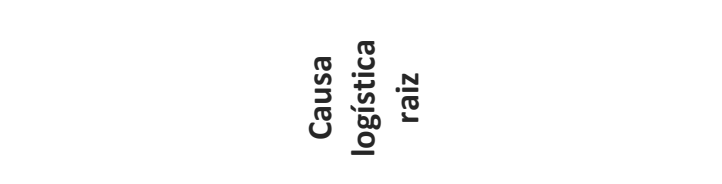 & $\frac{\frac{0}{2}}{\frac{\pi}{0}}$ & 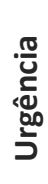 & 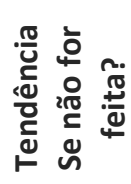 & 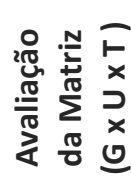 \\
\hline $\begin{array}{l}\text { O revendedor não possui um mapeamento de seu } \\
\text { período sazonal. }\end{array}$ & 4 & 5 & 4 & 80 \\
\hline $\begin{array}{lllr}\text { Devido algum erro } & \text { em } & \text { seu } \\
\text { sistema/impressão/internet ou falha } & \text { no } \\
\text { recebimento do XML. } & & & \\
\end{array}$ & 3 & 1 & 1 & 3 \\
\hline $\begin{array}{l}\text { Porque cliente não acompanhou as pendências } \\
\text { fiscais na SEFA. }\end{array}$ & 1 & 3 & 3 & 9 \\
\hline $\begin{array}{l}\text { Devido a falta de comunicação entre os setores } \\
\text { ocorre o desconto incorreto. }\end{array}$ & 3 & 4 & 4 & 48 \\
\hline $\begin{array}{l}\text { Porque cria pedidos sem o consentimento do } \\
\text { revendedor para bater a meta. }\end{array}$ & 4 & 5 & 5 & 100 \\
\hline $\begin{array}{l}\text { Pois não possuem um sistema de qualidade rígido } \\
\text { para a verificação de vasilhames não conformes. }\end{array}$ & 5 & 5 & 5 & 125 \\
\hline
\end{tabular}

Fonte: Autoria própria (2017) 
6o Passo - Proposição de ações de melhorias logísticas para eliminação/mitigação do problema

\section{Proposta do plano de ação para eliminação/mitigação das causas do problema} logístico, através de um método de gerenciamento de processos

Nesta etapa, foi aplicada a ferramenta $5 \mathrm{~W} 2 \mathrm{H}$ e em seguida a ferramenta META SMART, como base de planejamento para implantação do plano de melhoria, visando a mitigação/solução das causas logísticas raízes que provocam as devoluções de mercadorias na empresa objeto deste estudo. A causa logística raiz "A empresa não tem um sistema de qualidade para validação dos pedidos feitos pelos vendedores" foi classificada como a de maior emergência, conforme etapa anterior. Sendo assim, esta foi causa logística raiz considerada para a proposição do plano de ação, conforme o Quadro 7.

Mediante reunião realizada com os gestores envolvidos no processo, foi apresentado o plano $5 \mathrm{~W} 2 \mathrm{H}$ conforme descrito no quadro 7 , que teve a finalizade de debater o processo e definir metas a serem alcançadas deste plano das seguintes proposições: Criação de indicadores de desempenho e Treinamentos dos revededores pois não haverá custo para empresa. Segue no quadro 8 os resultados obtidos. 
Quadro 7 - Ferramenta 5w2h

\begin{tabular}{|c|c|c|c|c|c|c|}
\hline \multicolumn{7}{|c|}{ CAUSA LOGÍSTICA RAÍZ: NÃO POSSUI UM SISTEMA DE QUALIDADE RÍGIDO PARA INSPEÇÃO DE VASILHAMES NÃO CONFORMES } \\
\hline O QUE? & QUEM? & ONDE? & PORQUÊ? & QUANDO? & COMO? & QUANTO? \\
\hline $\begin{array}{l}\text { Criação de } \\
\text { indicadores de } \\
\text { desempenho. }\end{array}$ & $\begin{array}{l}\text { Gerente de } \\
\text { Produção e } \\
\text { Estagiário. }\end{array}$ & $\begin{array}{l}\text { Ferramenta } \\
\text { de Excel. }\end{array}$ & $\begin{array}{l}\text { Para monitorar motivo } \\
\text { de devolução. }\end{array}$ & Mensalmente. & $\begin{array}{c}\text { Criação de planilha de monitoramento } \\
\text { eletrônico usando como base os dados de } \\
\text { devolução. }\end{array}$ & $\begin{array}{l}\text { Realocação de } \\
\text { recursos internos. }\end{array}$ \\
\hline $\begin{array}{l}\text { Treinamento dos } \\
\text { envolvidos. }\end{array}$ & Consultoria AP. & Auditório. & $\begin{array}{l}\text { Para buscar soluções } \\
\text { para minimizar o } \\
\text { processo de devoluções. }\end{array}$ & Dois meses. & $\begin{array}{l}\text { Trabalhando com o autodesenvolvimento } \\
\text { profissional, mediante a ferramentas, } \\
\text { dinâmicas de grupo entendendo assim as } \\
\text { competencias necessárias a serem } \\
\text { desenvolvidas. }\end{array}$ & $1.000,00$ \\
\hline $\begin{array}{l}\text { Treinamentos } \\
\quad \text { dos } \\
\text { revendedores. }\end{array}$ & $\begin{array}{l}\text { Encarregado de } \\
\text { produção. }\end{array}$ & Auditório. & $\begin{array}{l}\text { Para entenderem } \\
\text { entenderem o que são } \\
\text { vasilhames com não } \\
\text { conformidade. }\end{array}$ & Semestral. & $\begin{array}{l}\text { Mediante apresentações de power point e } \\
\text { demonstração dos vasilhmes. }\end{array}$ & $\begin{array}{l}\text { Realocação de } \\
\text { recursos internos. }\end{array}$ \\
\hline $\begin{array}{l}\text { Criação de Check } \\
\text { list visual do } \\
\text { processo. }\end{array}$ & $\begin{array}{l}\text { Encarregado de } \\
\text { produção. }\end{array}$ & $\begin{array}{l}\text { Ferramenta } \\
\text { Office. }\end{array}$ & $\begin{array}{l}\text { Para monitorar os } \\
\text { possíveis gargalos no } \\
\text { processo. }\end{array}$ & Diariamente. & $\begin{array}{l}\text { Através de um check list-painel, o } \\
\text { encarregado irá fazer inspeções de amostras } \\
\text { e estará disponível para todos visualizarem. }\end{array}$ & 700,00 \\
\hline
\end{tabular}

Fonte: Autoria própria (2017) 
Quadro 8 - Ferramenta meta smart

\begin{tabular}{|c|c|c|c|c|}
\hline \multicolumn{5}{|c|}{ META SMART } \\
\hline ESPECÍFICO & MENSURÁVEL & REALIZÁVEL & RELEVANTE & $\begin{array}{c}\text { PRAZO } \\
\text { DEFINIDO }\end{array}$ \\
\hline $\begin{array}{l}\text { O gerente de } \\
\text { produção } \\
\text { junto ao } \\
\text { estagiário de } \\
\text { engenharia de } \\
\text { produção } \\
\text { deverá criar } \\
\text { indicadores } \\
\text { específicos. }\end{array}$ & $\begin{array}{l}\text { Quando } \\
\text { houver } \\
\text { redução } \\
\text { mensalmente } \\
\text { de motivos de } \\
\text { vasilhames } \\
\text { não } \\
\text { conformes. }\end{array}$ & $\begin{array}{c}\text { Deverá ser } \\
\text { realizado através } \\
\text { da ferramenta } \\
\text { office os } \\
\text { indicadores de } \\
\text { desempenho para } \\
\text { mensurar os } \\
\text { devidos motivos de } \\
\text { devolução de } \\
\text { vasilhames não } \\
\text { conformes. }\end{array}$ & $\begin{array}{l}\text { Com os } \\
\text { indicadores } \\
\text { poderá } \\
\text { classificar os } \\
\text { motivos e } \\
\text { assim realizar } \\
\text { ações para } \\
\text { minimizar os } \\
\text { retornos. }\end{array}$ & 5 meses \\
\hline $\begin{array}{l}\text { O encarregado } \\
\text { de produção } \\
\text { deverá criar } \\
\text { cursos para os } \\
\text { revendedores }\end{array}$ & $\begin{array}{c}\text { Quando } \\
\text { houver } \\
\text { redução } \\
\text { mensalmente } \\
\text { de vasilhames } \\
\text { conformes. }\end{array}$ & $\begin{array}{c}\text { Mediante auxilio } \\
\text { dos promotores, } \\
\text { deverão criar } \\
\text { realizar } \\
\text { cronogramas para } \\
\text { a realização das } \\
\text { palestras, } \\
\text { dinâmicas de } \\
\text { grupo, visitas } \\
\text { técnicas entre } \\
\text { outros que será } \\
\text { ministrada pelo } \\
\text { encarregado de } \\
\text { produção com } \\
\text { auxílio de seus } \\
\text { assistentes. }\end{array}$ & $\begin{array}{c}\text { Através de } \\
\text { treinamentos } \\
\text { constantes, os } \\
\text { revendedores } \\
\text { deverão se } \\
\text { integrar no } \\
\text { processo, } \\
\text { obtendo assim } \\
\text { o } \\
\text { conhecimento } \\
\text { de distinguir os } \\
\text { vasilhames } \\
\text { conformes. }\end{array}$ & 3 meses \\
\hline
\end{tabular}

Fonte: Autoria própria (2017)

\section{CONSIDERAÇÕES FINAIS}

Um dos objetivos das empresas é gerar satisfação ao cliente daquilo que se oferece pois consequentemente acaba gerando vários benefícios para a mesma. Sendo assim através da utilização do método criado por Beltrão e Galiza (2015) na empresa de uma distribuidora de GLP auxilio para a identificação no problema de devolução de mercadorias.

Inicialmente, formulou-se um fluxograma dos processos internos da distribuidora, assim como se obteve as quantidades de ocorrências de devoluções relacionadas ao número de notas fiscais e as causas julgadas diretamente associadas. Na etapa de associação das causas de devoluções aos componentes logísticos operacionais, verificou-se que o componente estoque e transporte não foram associado a nenhuma delas, visto que a análise dos motivos não conferiu nenhuma natureza relacionada a estes componentes. Entretanto, um dos maiores motivos da apresentação do estudo de caso foi o componente "Informação" caracterizou a maior porcentagem $(98,04 \%)$. 
Para identificação das causas principais, utilizou-se o Diagrama de Pareto, para o qual foram consideradas as causas que acumularam uma ocorrência de até $80 \%$ para cada componente logístico. Esta informação foi importante, pois ajudou a trabalhar de forma mais assertiva com as causas (motivos) que foram mais relevantes no processo. Posteriormente, utilizou-se as ferramentas "Diagrama de Causa e Efeito" e "5 Porquês" para identificar as causas logísticas raízes, por componente logístico, associadas ao problema principal que compreenderam com os seguintes motivos: revendedor não possui um mapeamento de seu período sazonal, devido algum erro em seu sistema/impressão/internet ou falha no recebimento do $X M L$, porque cliente não acompanhou as pendências fiscais na SEFA, devido a falta de comunicação entre os setores ocorre o desconto incorreto, porque cria pedidos sem o consentimento do revendedor para bater a meta, foram ligado ao componente informação e o único motivo associado ao componentes instalação foi que não possuem um sistema de qualidade rígido para a verificação de vasilhames não conformes.

Além disso, estas causas logísticas raízes foram hierarquizadas na Matriz GUT, e a que obteve maior destaque por apresentar maior "emergência" de resolução foi "Pois não possuem um sistema de qualidade rígido para a verificação de vasilhames não conformes" associada à causa - VASILHAMES COM NÃO CONFORMIDADE".

Assim, propôs-se um plano de ação para potencializar a mitigação/resolução desta causa, com quatro propostas: criação de indicadores de desempenho para monitorar motivo de devolução; Treinamento dos envolvidos para buscar soluções para minimizar o processo de devoluções, treinamentos dos revendedores para entenderem o que são vasilhames com não conformidade; criação de Check-list visual do processo para monitorar os possíveis gargalos no processo por meio da ferramenta $5 \mathrm{~W} 2 \mathrm{H}$ e finalmente foi definido mediante na ferramenta META SMART as seguintes metas: Criação de indicadores de desempenho e Treinamentos dos revendedores, de forma a minimizar essa quantidade de devoluções e gerenciar o atendimento correto dos pedidos dos clientes que deverá ser cumprida mediante a cronograma proposto.

Como proposta de estudos futuros recomenda-se realizar um estudo de mapeamento do setor produtivo junto aos resultados definido na ferramenta meta smart e assim realizar a classificação desses motivos para que consiga a minimização dessas não conformidades, pois este motivo está afetando diretamente o consumidor final. 


\title{
Quality improvement on logistical service: an application of a method to reduce returns in a distributor of oil
}

\author{
ABSTRACT
}

\begin{abstract}
Market is becoming more competitive, which causes companies to seek better features to achieve customer satisfaction and loyalty. In distribution companies, one of the problems that influence these objectives is the return of goods, which frequently occurs due to low performance levels in logistics processes. Therefore, there is a need to improve the quality of these services to reduce nonconformities and increase reliability. For this purpose, this study aimed to apply a method for quality improving in logistics services and reduce returns of goods in an oil derivatives distributor, located in the city of Belém-PA. This application resulted in the diagnosis of the process, which identified "information" as the logistic driver with the main index of returns, however the emergency root cause of "does not have a rigid quality system for inspection of non-conformities" was related to logistical driver "facility". Hence, the SMART goals created were: define performance indicators and train retailers to seek the solution / mitigation of the main problem.
\end{abstract}

KEYWORDS: Logistical Drivers. Quality in Services. Goods Return. 


\section{REFERÊNCIAS}

BALLOU, R. H. Logística Empresarial: transportes, administração de materiais e distribuição física. 1. ed. São Paulo: Atlas, 2009.

BALLOU, Ronald H. et al. Logística empresarial. São Paulo: Atlas, 2001.

BELTRÃO, Aline Maria da Cunha; GALIZA, Murilo dos Santos. MELHORIA DA QUALIDADE DO SERVIÇO LOGÍSTICO: Um método voltado à redução de devoluções em distribuidoras de multiprodutos. $72 \mathrm{f}$. Trabalho de Conclusão de Curso (Graduação em Engenharia de Produção) - Universidade do Estado do Pará. Belém, 2015.

CHOPRA, Sunil; MEINDL, Peter. Gerenciamento da Cadeia de Suprimentos: Estratégia, Planejamento e Operação. São Paulo: Pearson, 2003.

CHOPRA, Sunil; MEINDL, Peter. Gestão da cadeia de suprimentos: estratégia, planejamento e operações. 4. ed. São Paulo: Pearson Prentice Hall, 2011.

HAMMER, Michael; CHAMPY, James. Reengenharia: revolucionando a empresa em função dos clientes, da concorrência e das grandes mudanças da gerência. Rio de Janeiro: Campus, 1994.

HAMMER, Michael; CHAMPY, James. Reengenharia: revolucionando a empresa em função dos clientes, da concorrência e das grandes mudanças da gerência. Rio de Janeiro: Campus, 1994.

HARRINGTON, H. James. Aperfeiçoando processos empresarias. São Paulo: Makron Books, 1997.

MIGUEL, P.A.C. Qualidade: enfoques e ferramentas.. 1 ed. São Paulo: Artliber, 2006.

OLIVEIRA, C.C. Aplicação de ferramentas da qualidade no acompanhamento e controle de perdas de embalagens da produção de resfriados temperados [online]. Disponível na Internet via correio eletrônico:

http://www.ingepro.com.br/index.php/ingepro/article/view/232/196. Revista INGEPRO. Vol. 2, No 5, 2010

OLIVEIRA, Ana Rachel Fonseca de; VIEIRA, Thais Ferreira. Etapas para a 
EspecializaÇÃo em Nefrologia Multidisciplinar, Universidade Federal do Maranhão. Una-sus/ufma., Maranhão, 2014.

RODRIGUES, Washington Luiz Halley Portes; SANTIN, Nilson Jair. Gerenciamento da Cadeia de Suprimentos. Disponível em:

<ftp://www.usit.br/pub/revint/97 37.pdf>. Acesso em: 14 maio 2011.

SILVA, Edna Lúcia da; MENEZES, Estera Muszkat. Metodologia da pesquisa e elaboração de dissertação. 2005. ed. Florianópolis: Ufsc, 2005.

SLACK, N. et alli. (1997). Administração da Produção, Editora Atlas, São Paulo, SP

SLACK, Nigel et al. ADMINISTRAÇÃO DA PRODUÇÃO. São Paulo: Atlas, 2009.

SOLIMAN, Samir; SRINATH, Mandyam. Continuous and Discrete Signals and Systems. 2. ed. New Jersey: Prentice Hall, 1998.

TRISTÃO, Renata Guimarães Couto (2011) - A importância das ações corretivas e ações preventivas nos sistemas de gestão da qualidade - um estudo em empresas certificadas isso 9001 no estado do rio de janeiro. Niterói, Rio de Janeiro. Universidade Federal Fluminense. Mestrado Profissional em Sistemas de Gestão. Disponível em: . Acesso em: 02. nov.2012.

Recebido: 05 mar. 2017

Aprovado: 27 out. 2017

DOI: 10.3895/gi.v13n3.5637

Como citar:

BELTRÃO, A. M.; MARTINS, V. W. B. Melhoria da qualidade do serviço logístico: aplicação de um metódo voltado à redução de devoluções em uma distribuidora de derivados de petróleo. R. Gest. Industr., Ponta Grossa, v. 13, n. 3, p. 82-111, set./nov. 2017. Disponível em: <https://periodicos.utfpr.edu.br/rgi>. Acesso em: $\mathrm{XXX}$

Correspondência:

Aline Maria Beltrão

Tv angustura 1402, Apt 202, Belém, Pará, Brasil.

Direito autoral: Este artigo está licenciado sob os termos da Licença Creative Commons-Atribuição 4.0 Internacional. 


\section{Apêndice A}

\begin{tabular}{|c|c|c|c|c|c|}
\hline \multicolumn{2}{|c|}{$\begin{array}{c}\text { INFORMAÇÃO - Motivo - NÃO DISPOR DOS } \\
\text { VASILHAMES VAZIOS. }\end{array}$} & 1 PORQUE & 2 PORQUE & 3 PORQUE & 4 PORQUE \\
\hline 4 Porquê? & $\begin{array}{c}\text { Por que o revendedor não possui uma } \\
\text { demanda prevista? }\end{array}$ & $\begin{array}{c}\text { Por que o revendedor não } \\
\text { dispõe de vasilhames } \\
\text { vazios? }\end{array}$ & $\begin{array}{c}\text { Por que esses revendedores } \\
\text { não tiveram a venda } \\
\text { prevista? }\end{array}$ & $\begin{array}{l}\text { Por que o revendedor } \\
\text { realiza o pedido mesmo } \\
\text { tendo vasilhames cheios? }\end{array}$ & $\begin{array}{c}\text { Por que o revendedor } \\
\text { não possui uma demanda } \\
\text { prevista? }\end{array}$ \\
\hline $\begin{array}{l}\text { Causa } \\
\text { Raiz }\end{array}$ & $\begin{array}{l}\text { O revendedor não possui um } \\
\text { mapeamento de seu período sazonal. }\end{array}$ & $\begin{array}{l}\text { Porque os mesmos não } \\
\text { tiveram a venda prevista. }\end{array}$ & $\begin{array}{l}\text { Porque o realizou o pedido } \\
\text { mesmo tendo muitos } \\
\text { vasilhames cheios }\end{array}$ & $\begin{array}{l}\text { Porque o revendedor não } \\
\text { possui uma demanda } \\
\text { prevista }\end{array}$ & $\begin{array}{l}\text { O revendedor não possui } \\
\text { um mapeamento de seu } \\
\text { período sazonal. }\end{array}$ \\
\hline \multicolumn{2}{|c|}{$\begin{array}{l}\text { INFORMAÇÃO - Motivo - CLIENTE NÃO EMITIU NOTA } \\
\text { FISCAL DE RETORNO DOS VASILHAMES. }\end{array}$} & 1 PORQUE & 2 PORQUE & 3 PORQUE & 4 PORQUE \\
\hline 2 Porquê? & $\begin{array}{l}\text { Por que o cliente encontra-se com } \\
\text { alguma irregularidade? }\end{array}$ & $\begin{array}{l}\text { por que o cliente não } \\
\text { emitiu nota fiscal de } \\
\text { retorno dos vasilhames? }\end{array}$ & $\begin{array}{c}\text { Por que o cliente encontra- } \\
\text { se com alguma } \\
\text { irregularidade? }\end{array}$ & & \\
\hline $\begin{array}{l}\text { Causa } \\
\text { Raiz }\end{array}$ & $\begin{array}{l}\text { Devido algum erro em seu } \\
\text { sistema/impressão/internet ou falha no } \\
\text { recebimento do XML. }\end{array}$ & $\begin{array}{l}\text { Porque o cliente encontra- } \\
\text { se com alguma } \\
\text { irregularidade }\end{array}$ & $\begin{array}{c}\text { Devido algum erro em seu } \\
\text { sistema/impressão/internet } \\
\text { ou falha no recebimento do } \\
\text { XML }\end{array}$ & & \\
\hline \multicolumn{2}{|c|}{$\begin{array}{l}\text { INFORMAÇÃO - Motivo - CLIENTE NÃO HABILITADO } \\
\text { NO SINTEGRA. }\end{array}$} & 1 PORQUE & 2 PORQUE & 3 PORQUE & 4 PORQUE \\
\hline 3 Porquê? & Por que o contador deixou de pagar? & $\begin{array}{c}\text { Por que o cliente se } \\
\text { encontra não habilitado no } \\
\text { Sintegra? }\end{array}$ & $\begin{array}{l}\text { Por que o cliente possui } \\
\text { irregularidades fiscal? }\end{array}$ & $\begin{array}{l}\text { Por que o contador deixou } \\
\text { de pagar? }\end{array}$ & \\
\hline $\begin{array}{l}\text { Causa } \\
\text { Raiz }\end{array}$ & $\begin{array}{l}\text { Porque cliente não acompanhou as } \\
\text { pendências fiscais na SEFA. }\end{array}$ & $\begin{array}{l}\text { Porque possui } \\
\text { irregularidades fiscal }\end{array}$ & $\begin{array}{l}\text { Porque o contador deixou de } \\
\text { pagar as pendências fiscais }\end{array}$ & $\begin{array}{c}\text { Porque cliente não } \\
\text { acompanhou as } \\
\text { pendências fiscais na SEFA. }\end{array}$ & \\
\hline \multicolumn{2}{|c|}{ INFORMAÇÃO - Motivo - DESCONTO INCORRETO. } & 1 PORQUE & 2 PORQUE & 3 PORQUE & 4 PORQUE \\
\hline 4 Porquê? & $\begin{array}{l}\text { Por que os setores não são totalmente } \\
\text { integrados? }\end{array}$ & $\begin{array}{l}\text { Por que o cliente encontra- } \\
\text { se com o desconto } \\
\text { incorreto? }\end{array}$ & $\begin{array}{l}\text { Por que houve erro em sua } \\
\text { programação? }\end{array}$ & $\begin{array}{l}\text { Por que houve falha na } \\
\text { comunicação entre os } \\
\text { setores? }\end{array}$ & $\begin{array}{l}\text { Por que os setores não } \\
\text { são totalmente } \\
\text { integrados }\end{array}$ \\
\hline $\begin{array}{l}\text { Causa } \\
\text { Raiz }\end{array}$ & $\begin{array}{l}\text { Devido a falta de comunicação entre os } \\
\text { setores ocorre o desconto incorreto. }\end{array}$ & $\begin{array}{l}\text { Porque houve erro em sua } \\
\text { programação }\end{array}$ & $\begin{array}{c}\text { Porque houve falha na } \\
\text { comunicação entre os } \\
\text { setores }\end{array}$ & $\begin{array}{l}\text { Porque os setores não são } \\
\text { totalmente integrados }\end{array}$ & $\begin{array}{c}\text { Devido a falta de } \\
\text { comunicação entre eles }\end{array}$ \\
\hline
\end{tabular}

R. Gest. Industr., Ponta Grossa, v. 13, n. 3, p. 82-111, set./nov. 2017. 


\begin{tabular}{|c|c|c|c|c|c|}
\hline \multicolumn{2}{|c|}{$\begin{array}{c}\text { INFORMAÇÃO - Motivo - CLIENTE NÃO SOLICITOU O } \\
\text { PEDIDO. }\end{array}$} & 1 PORQUE & 2 PORQUE & 3 PORQUE & 4 PORQUE \\
\hline 3 Porquê? & $\begin{array}{l}\text { Por que a célula de atendimento } \\
\text { programou algo que o cliente não pediu? }\end{array}$ & $\begin{array}{l}\text { Por que esses pedidos } \\
\text { foram enviados aos } \\
\text { clientes? }\end{array}$ & $\begin{array}{l}\text { Por que esses pedidos } \\
\text { estavam registrados no } \\
\text { sistema? }\end{array}$ & $\begin{array}{l}\text { Por que a célula de } \\
\text { atendimento programou } \\
\text { algo que o cliente não } \\
\text { pediu? }\end{array}$ & \\
\hline $\begin{array}{l}\text { Causa } \\
\text { Raiz }\end{array}$ & $\begin{array}{l}\text { Porque cria pedidos sem o } \\
\text { consentimento do revendedor para } \\
\text { bater a meta. }\end{array}$ & $\begin{array}{l}\text { Porque os pedidos estavam } \\
\text { devidamente registrados } \\
\text { no sistema de pedidos }\end{array}$ & $\begin{array}{l}\text { Porque foram solicitados } \\
\text { pelo programados pela } \\
\text { célula de atendimento. }\end{array}$ & $\begin{array}{l}\text { Porque cria pedidos sem o } \\
\text { consentimento do } \\
\text { revendedor para bater a } \\
\text { meta. }\end{array}$ & \\
\hline \multicolumn{2}{|c|}{$\begin{array}{l}\text { INFORMAÇÃO - Motivo - VASILHAMES COM NÃO } \\
\text { CONFORMIDADE. }\end{array}$} & 1 PORQUE & 2 PORQUE & 3 PORQUE & 4 PORQUE \\
\hline 4 Porquê? & Porque foram mal inspecionados? & $\begin{array}{l}\text { Por que os vasilhames se } \\
\text { encontram com não } \\
\text { conformidade? }\end{array}$ & $\begin{array}{l}\text { Por que os vasilhames se } \\
\text { encontram amassados, mal } \\
\text { pintados, com vazamento...? }\end{array}$ & $\begin{array}{l}\text { Por que ocorreu erro } \\
\text { durante a produção? }\end{array}$ & $\begin{array}{l}\text { Porque foram mal } \\
\text { inspecionados? }\end{array}$ \\
\hline $\begin{array}{l}\text { Causa } \\
\text { Raiz }\end{array}$ & $\begin{array}{l}\text { Pois não possuem um sistema de } \\
\text { qualidade rígido para a verificação de } \\
\text { vasilhames não conformes. }\end{array}$ & $\begin{array}{c}\text { Pois encontram-se } \\
\text { amassados, mal pintados, } \\
\text { com vazamento... }\end{array}$ & $\begin{array}{l}\text { Devido a ocorrência de erro } \\
\text { durante a produção }\end{array}$ & $\begin{array}{l}\text { Porque foram mal } \\
\text { inspecionados }\end{array}$ & $\begin{array}{l}\text { Pois não possuem um } \\
\text { sistema de qualidade } \\
\text { rígido para a verificação } \\
\text { de vasilhames não } \\
\text { conformes. }\end{array}$ \\
\hline
\end{tabular}

